\title{
Uso de software como mediador na aprendizagem da leitura: estudo de caso
}

\author{
Aline Sberse Sengik \\ Prefeitura Municipal de Lagoa Vermelha - Lagoa Vermelha - RS - Brasil \\ Carla Beatris Valentini \\ Universidade de Caxias do Sul - Caxias do Sul - RS - Brasil \\ Jordana Wruck Timm \\ Pontifícia Universidade Católica do Rio Grande do Sul - Porto Alegre - RS Brasil
}

\section{Resumo}

Este artigo tem por objetivo refletir sobre o uso de tecnologias digitais na aprendizagem da leitura inicial, especialmente com crianças que apresentam queixas relativas a seu desempenho escolar. Nesse sentido, fundamenta-se, principalmente, em autores como Vygotsky, Soares, Kleiman, Solé, Alliende e Condemarín e Santarosa et al. O trabalho delineia-se como um Estudo de Caso realizado a partir da observação de uma criança interagindo com o software Menino Curioso. A análise buscou compreender se o uso dessa ferramenta pode contribuir para o desenvolvimento das habilidades de decodificação pressupostas pela leitura. Utilizou-se a análise textual discursiva nos resultados encontrados, o que permitiu perceber que o uso do software auxiliou a criança na discriminação da maioria das letras, além de promover maior autonomia, espontaneidade e motivação.

Palavras-chave: Leitura; aprendizagem; tecnologia educacional.

\section{Use of software as a mediator in reading learning: a case study}

\begin{abstract}
This article aims to reflect about the use of digital technologies in learning the initial reading, especially with children who have complaints about their school performance. In this sense, it is based mainly on authors such as Vygotsky, Soares, Kleiman, Solé, Alliende and Condemarín and Santarosa et al. The work is outlined as a Case Study conducted from the observation of a child interacting with the Curious Boy software. The analysis sought to understand if the use of this tool can contribute to the development of decoding abilities presupposed by reading. We used the discursive textual analysis in the results found, which allowed us to perceive that the use of the software helped the child in the discrimination of most letters, besides promoting greater autonomy, spontaneity and motivation.
\end{abstract}

Keywords: Reading; learning; educational technology.

\section{Uso de software como mediador en el aprendizaje de la lectura: estudio de caso}

\section{Resumen}

Este artículo tiene por objetivo reflexionar sobre el uso de tecnologías digitales en el aprendizaje de la lectura inicial, especialmente con niños que presentan quejas relativas a su desempeño escolar. En este sentido, se fundamenta, principalmente, en autores como Vygotsky, Soares, Kleiman, Solé, Alliende y Condemarín y Santarosa et al. El trabajo se delinea como un Estudio de Caso realizado a partir de la observación de un niño interactuando con el software Menino Curioso. El análisis buscó comprender si el uso de esta herramienta puede contribuir al desarrollo de las habilidades de decodificación presupuestadas por la lectura. Se utilizó el análisis textual discursivo en los resultados encontrados, lo que permitió percibir que el uso del software ayudó al niño en la discriminación de la mayoría de las letras, además de promover mayor autonomía, espontaneidad y motivación.

Palabras clave: Lectura; aprendizaje; tecnología educacional. 


\section{Introdução}

Partindo da concepção de que a aprendizagem ocorre na interação com o outro e/ou com os objetos de conhecimento que fazem parte do contexto social e que, nesse processo, as tecnologias digitais podem ser utilizadas como aliadas para a apropriação do conhecimento, propõe-se, neste artigo, uma reflexão sobre o uso do software Menino Curioso no desenvolvimento das habilidades pressupostas pela decodificação e implicadas na leitura.

A experiência social, entendida como fonte de desenvolvimento, origina-se na relação com o outro. Esse processo de interação é, de acordo com Vygotski (1996), um processo de educação, pois o homem se humaniza quando, por meio desse processo, internaliza significados proporcionados pela cultura, adquiridos pelas gerações precedentes. Desse modo, à educação fica a incumbência de assegurar às crianças a apropriação desse conhecimento. Para o autor (Vygotsky, 1991), é difícil falar de aprendizado ${ }^{1}$ sem considerar o desenvolvimento, os quais estão inter-relacionados desde o primeiro dia de vida da criança.

Vygotsky (1991) afirma que há, pelo menos, dois níveis de desenvolvimento. O primeiro diz respeito ao nível de desenvolvimento real, ou seja, o nível de desenvolvimento das funções mentais da criança que resultam de certos ciclos de desenvolvimento já estruturados. Em geral, esse nível é o que determina, em testes psicológicos, a idade mental de uma criança, admitindo-se que só é indicativo de capacidade mental do sujeito aquilo que ele consegue realizar sozinho. O segundo, nível de desenvolvimento potencial, implica a Zona de Desenvolvimento Proximal (ZDP), que é entendida como:

\footnotetext{
... a distância entre o nível de desenvolvimento real, que se costuma determinar através da solução independente de problemas, e o nível de desenvolvimento potencial, determinado através da solução de problemas sob a orientação de um adulto ou em colaboração de companheiros mais capazes (Vygotsky, 1991, p. 97).
}

Neste trabalho, o conceito de inteligência abarca essa noção de ZDP que permite sair do padrão estável dos testes de inteligências tradicionais, bem como avaliar a criança num processo dinâmico, visando o potencial que ela pode atingir, retirando assim "o foco da deficiência para apostar no processo de desenvolvimento humano, em suas diferentes peculiaridades." (Santarosa, Conforto, Passerino, Estabel, Carneiro, \& Geller, 2010, p. 21, grifo das autoras).

De acordo com Vygotsky (1991), a aprendizagem começa muito antes de a criança frequentar o ensino formal, pois quando ingressa no primeiro ano escolar, já possui uma linguagem oral bem desenvolvida. Segundo o autor, a linguagem é essencial para a construção de conhecimentos e, também, pode ser considerada a responsável pela estruturação do pensamento. O mesmo autor acrescenta que

1 O termo aprendizado é entendido, neste estudo, como sinônimo de aprendizagem. pelo uso de instrumentos e pela internalização dos signos ${ }^{2}$, produzidos culturalmente, a criança se desenvolve cognitivamente. Nesse sentido, conforme Vygotsky (1991, p. 62), o instrumento tem como função servir de condutor da influência humana em relação ao objeto da atividade; é externamente orientado; deve levar, necessariamente, a mudanças nos objetos. Já o signo, diferentemente, "não modifica em nada o objeto da operação psicológica. Constitui um meio da atividade interna dirigida para o controle do próprio indivíduo; o signo é orientado internamente".

Assim, entende-se que as sociedades criam instrumentos e signos que, historicamente, modificam e medeiam a relação do sujeito com o mundo. É nessa interação com as práticas sociais que a criança vai se constituindo e construindo conhecimentos. É nesse contexto que o presente estudo aborda a importância dos instrumentos como ferramentas cognitivas que, quando associados ao uso de ambientes digitais de comunicação, podem promover, enquanto mediadores, a socialização, a interação, a cooperação, a construção e o desenvolvimento das funções mentais superiores (Santarosa \& cols., 2010).

\section{Queixas escolares e softwares educacionais}

Neste item, fazem-se algumas considerações acerca das queixas de dificuldades que ocorrem no processo de escolarização, o que conforme Facci e Souza (2014) são frequentes na (s) escola(s), e sobre a relevância do uso de recursos digitais, nesse caso, os softwares educacionais para um ensino diferenciado.

As implicações que a ZDP tem para o processo de instrução do aprendiz podem ser muitas, desde que o professor observe os níveis de desenvolvimento real e potencial do aluno e atue como mediador, intervindo, se necessário, em sua aprendizagem. Assim, acredita-se que o uso de softwares ${ }^{3}$ educacionais pode auxiliar o sujeito na apropriação de conhecimento. Para Santarosa e cols. (2010), estudos têm demonstrado que as tecnologias digitais vêm se apresentado como aliadas para o ensino, inclusive para a aprendizagem de alunos que exigem uma educação especializada.

A educação especializada pode ser complementar ou suplementar, sendo ofertada, respectivamente, para o aluno que apresenta algum tipo de deficiência física, visual, mental, surdez e/ou com altas habilidades. No caso específico daqueles com queixas escolares, há uma grande quantidade/diversidade de fatores envolvidos no processo educativo, o que torna indispensável proporcionar a elas, em todo o percurso de seu desenvolvimento, a possibilidade de

2 Para Vygotsky (1991), o signo é a representação direta de um objeto.

3 Software refere-se a toda documentação envolvida, que inclui o programa. Esse é um algoritmo executável, isto é, "uma sequência de passos lógicos para resolver determinado problema" (Santarosa \& cols., 2010). 
ter acesso a um ensino significativo e que potencialize novas formas de crescimento, socialização e aprendizagens.

Em função da complexidade acerca das descrições/ entendimentos sobre dificuldades de aprendizagem, neste artigo utiliza-se "A concepção teórica que nos permite analisar o processo de escolarização - e não os problemas de aprendizagem - desloca-se o eixo da análise do indivíduo para a escola e o conjunto de relações institucionais, históricas, psicológicas, pedagógicas e políticas que se fazem presentes e constituem o dia a dia escolar." (Souza, 2008, p. 5, grifo da autora).

Ou seja, as queixas escolares compõem o contexto educacional, por isso é preciso atentar quando somente a criança é responsabilizada pelo fracasso, tendo em vista que essa dificuldade, para atingir a aprendizagem esperada, pode ser consequência do processo de escolarização.

Consoante os preceitos vygotskyanos, as leis do desenvolvimento da criança deficiente ${ }^{4}$ são as mesmas que as de qualquer outra. São as relações que se estabelecem entre diferentes funções mentais que se constituem de modo diferenciado nesses sujeitos (Vygotski, 1997). Isso evidencia que crianças com limitações podem desenvolver muitas habilidades, desde que se busquem alternativas para o processo. É necessário trabalhar - com a estimativa das potencialidades da criança - habilidades que, para tornarem-se desenvolvimento efetivo, exijam o processo de aprendizagem, os mediadores e as ferramentas disponíveis em ambiente adequado (Vasconcellos \& Valsiner, 1995).

O desenvolvimento de recursos de acessibilidade pode neutralizar barreiras causadas pelas dificuldades, assim como o uso adequado das tecnologias digitais tem se apresentado como aliado no processo de inclusão (Santarosa \& cols., 2010). Isso exige que o professor amplie seu papel, agindo como mediador, que acolhe as diferenças e busca se instrumentalizar para lidar com as diversidades em sua aula.

Nesse sentido, o uso de softwares educacionais em sala de aula pode impulsionar a aprendizagem, permitindo por meio de suas funções lúdica e educativa uma maior interação, motivação e autonomia do aluno. Entretanto, como nos explicam Santarosa \& cols. (2010), para atender objetivos educacionais, estabelecidos previamente, é necessário discernimento de que o uso de software no contexto da educação tem potencialidades e, também, limitações.

Por isso, ao docente cabe verificar as potencialidades do computador como ferramenta pedagógica, assim como conhecer o aluno, avaliar suas demandas e habilidades, observando seu nível de desenvolvimento real para selecionar um aplicativo adequado que possa atuar em sua ZDP, propiciando ao aprendiz interações que promovam aprendizagens significativas.

Para Santarosa \& cols. (2010, p. 273, grifo nosso), "Todos os softwares podem ser usados numa perspectiva educacional". Diante disso, "é importante que o mediador no uso do software seja coerente à escolha". Nesse sentido, e tendo em vista que eles podem propiciar aprendizagens

4 Neste estudo, adota-se criança com queixas escolares. desafiadoras, desde que sejam conhecidos pelo professor e utilizados de forma a explorar suas possibilidades, os softwares podem auxiliar no processo de leitura, de escrita, "na abstração, na construção de conceitos e em outros processos cognitivos".

Em função de todas as oportunidades que essas ferramentas digitais podem oferecer, sugere-se a utilização desses recursos para auxiliar no desenvolvimento das habilidades de decodificação implicadas na leitura, especialmente com aquela criança que leva mais tempo para desenvolvê-las, como será discutido na sequência deste trabalho.

\section{O aprendizado da leitura: habilidades de decodificação}

Neste item, apresenta-se o que se entende por alfabetização e letramento, além de algumas considerações acerca da leitura ${ }^{5}$, bem como das habilidades de decodificação pressupostas por ela. Para Soares (2003, p. 91-92), alfabetização pode ser compreendida como o "processo pelo qual se adquire o domínio de um código e das habilidades de utilizá-lo para ler e escrever, ou seja: o domínio da tecnologia - do conjunto de técnicas - para exercer a arte e ciência da escrita".

Tem-se utilizado o termo letramento, partindo da ideia de que, para ler e compreender o que se está lendo, é necessário fazer uso competente e frequente da leitura. Como afirma Soares (2003), para tornar-se letrado, o indivíduo precisa envolver-se nas práticas sociais de leitura e de escrita. A leitura, aqui, é concebida como uma prática complexa, cultural, dinâmica, construída socialmente na interação com o outro e/ou com os objetos de conhecimento.

Para Kleiman (2012), a aprendizagem formal da leitura ocorre na interação -especialmente entre colegas e professores- em um contexto criado para oportunizar ao aluno a compreensão daquilo a que se propõe ler. A partir desse entendimento, ao se receber um aluno na escola é fundamental conhecê-lo, pois, de acordo com Solé (1998), as crianças se mostram muito hábeis quanto ao uso da linguagem verbal, além de utilizarem estruturas linguísticas complexas quando iniciam o processo de aprender a ler e a escrever.

Ferreiro e Teberosky (1999, p. 26) já chamaram a atenção para as relações que se estabelecem entre a escrita e a linguagem oral. A criança já ingressa no ensino formal com um saber linguístico ${ }^{6}$, além de apresentar hipóteses referentes ao funcionamento da escrita. Então, tudo muda se supomos que o indivíduo que vai escrever já possui (ou não) conhecimento sobre sua língua materna.

\footnotetext{
5 Embora este estudo pretenda tratar aspectos relacionados à leitura inicial, sempre que for necessário dar-se-á atenção à escrita, ainda que apresentem processos de aprendizagem bastante distintos, pois como salienta Solé (1998, p. 64), "nas primeiras etapas da aprendizagem, leitura e escrita se apóiam mutuamente [...]".

6 Saber linguístico refere-se ao conhecimento não verbalizado, geralmente implícito, que nos permite falar português como falantes nativos, abrangendo o conhecimento da pronúncia, do vocabulário, das regras e do uso da língua (Kleiman, 2011).
} 
$\mathrm{Na}$ abordagem vygotskyana, quando os processos de leitura e escrita se iniciam, a escola deve considerar as apropriações das crianças em relação às suas habilidades já desenvolvidas, investigando os conhecimentos prévios que a criança possui, e, a partir daí, organizar um ensino que, de fato, resulte em aprendizagens novas e/ou mais complexas (Vygotsky, Luria, \& Leontiev, 1998).

Luria (1988) contribui nesse sentido, quando explica que as crianças iniciam o desenvolvimento da escrita antes de estarem expostas a um processo de escolarização formal. O período, anterior à aprendizagem escolar, conhecido como pré-história da escrita pode ser entendido da seguinte maneira:

No começo, a criança relaciona-se com coisas escritas sem compreender o significado da escrita; no primeiro estágio, escrever não é um meio de registrar algum conteúdo específico, mas um processo autocontido, que envolve a imitação de uma atividade do adulto, mas que não possui, em si mesmo, significado funcional. Esta fase é caracterizada por rabiscos não-diferenciados; a criança registra qualquer idéia com exatamente os mesmos rabiscos. Mais tarde... começa a diferenciação: o símbolo adquire um significado funcional e começa graficamente a refletir o conteúdo que a criança deve anotar. (Luria, 1988, pp. 180-181).

Assim, tanto a escrita quanto o processo de leitura envolvem operações complexas. Ler não é, somente, verbalizar uma palavra escrita, é saber tratá-la como signo, atribuindo-lhe sentido. Como afirma Vygotsky (1998, p. 150), "uma palavra sem significado 7 é um som vazio". Para que tudo isso ocorra, conforme Solé (1998, p. 56), é vital que adultos, que tenham interesse e saibam ensinar, se disponham "a tornar acessível a linguagem escrita para as crianças sob sua responsabilidade, o que implica observá-las e ajudá-las a ir além de onde se encontram". Dito isso, evidencia-se que a aprendizagem da leitura e da escrita se constrói em meio a atividades em que a criança interage com os outros e/ou com os objetos de conhecimento, e que, para a criança ser capaz de ler, escrever e compreender, é necessário o auxílio de um adulto ou de um colega mais experiente que possa instruí-la.

A hipótese que se tem é a de que as tecnologias digitais ocasionam mudanças não apenas nas formas de acesso à informação, mas também em novas formas de conhecimento, de processos cognitivos, de linguagens, que levam a "... conseqüências sociais, cognitivas e discursivas, e estejam, assim, configurando um letramento digital, isto é, um certo estado ou condição que adquirem os que se apropriam da nova tecnologia digital e exercem práticas de leitura e de escrita na tela" (Soares, 2002, p. 151).

A partir dessa ideia - de que as práticas de leitura e escrita na tela oportunizam diferentes formas de aprendizagem - é que se propõe o uso de softwares educacionais como auxílio e/ou suporte na promoção do envolvimento do aluno com as habilidades que subjazem o processo de

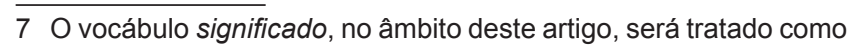
sentido. decodificação da leitura. A decodificação ${ }^{8}$ pode ser entendida, conforme Alliende e Condemarín (1987, p. 25), como "capacidade para identificar um signo gráfico por um nome ou por um som. Capacidade de transformar os signos escritos em linguagem oral. Capacidade de decifrar o código de uma mensagem e captar seu significado". O docente pode facilitar o acesso ao código valorizando e aproveitando o conhecimento prévio que a criança leva à escola.

Cabe lembrar que, nessa operação, cada sujeito terá um desempenho diferente, independente de apresentar dificuldades no processo de escolarização ou não, pois as bagagens e experiências são únicas. As habilidades de decodificação, aqui abordadas, referem-se às citadas por Alliende e Condemarín (2005), ou seja, reportam preponderantemente à capacidade de correspondência letra-som (aprendizagem dos fonemas ${ }^{9}$ ) enfatizando o reconhecimento de palavras. Sugere-se que essas habilidades sejam ensinadas de modo direto e explícito. Nessas operações, o professor pode utilizar diferentes maneiras para identificar/ pronunciar/recordar traços que distinguem e se assemelham entre as letras e as palavras, além de técnicas e estratégias que auxiliam a construção do sentido.

Conforme Alliende e Condemarín (2005), para aprender a ler é importante que a criança tenha um bom repertório de palavras e, também, o domínio do vocabulário visual. Essa constatação é realizada sem a necessidade de sonorizar os fonemas, isto é, sem que a criança precise oralizar os sons. O reconhecimento instantâneo se dá através da forma ou do contorno das palavras, permitindo que o sujeito compreenda seu significado. É com base nessa construção de imagens visuais das palavras e pela discriminação de letras e palavras que a criança vai formando progressivamente um vocabulário visual.

Esses autores (Alliende \& Condemarín, 2005) ainda mencionam a relevância de o leitor desenvolver uma consciência fonológica, que se refere à habilidade metalinguística ${ }^{10}$. Esse aprendizado auxilia a criança no reconhecimento de que existem palavras mais curtas, mais longas, que rimam etc.. Possibilita, também, o entendimento acerca da estrutura sonora - das relações entre letras e sons. Nesse processo, segundo Alliende e Condemarín (2005), as crianças vão entendendo que existe uma correspondência entre os sons da língua e sua representação gráfica, desenvolvendo a habilidade de reconhecer que as letras podem substituir os sons e que esses podem ser combinados para formar palavras.

Portanto, a decodificação implica identificar/reconhecer letras/palavras. Para isso, há a necessidade de desenvolver algumas habilidades, dentre elas a de estabelecer a

8 Neste artigo, serão tratados aspectos referentes ao processo de decodificação implicados pela leitura, contudo, deve-se ressaltar que embora essa operação seja fundamental para se dar a leitura inicial, ela é insuficiente para ocorrer a leitura compreensiva.

9 “... o fonema é a unidade estrutural mínima em seu sistema de sons que torna possível diferenciar as significações." (Aliende \& Condemarín, 2005, p. 200).

10 Essa habilidade permite refletir sobre algumas características da linguagem que não correspondem à linguagem natural -verbos, núcleo do sujeito ou artigo definido (Aliende \& Condemarín, 2005). 
correspondência letra-som, enfatizando o reconhecimento das palavras instantaneamente, ou seja, de forma rápida e inconsciente ${ }^{11}$. Essa operação - junto a pistas estruturais e contextuais - é o que permite à criança a automatização do processo de decodificação das palavras (Aliende \& Condemarín, 2005).

De acordo com Solé (1998, p. 92), "a motivação está intimamente relacionada às relações afetivas que os alunos possam ir estabelecendo com a língua escrita". Como já alertava Vygotsky (1991), a leitura e a escrita não podem ser ensinadas de forma mecânica, pois tende a inibir o desenvolvimento da criança. A leitura e a escrita devem ser ensinadas como uma atividade cultural complexa, ativando o interesse e a necessidade do sujeito. Por isso, reitera-se a importância de o docente utilizar softwares educacionais, alternando as ferramentas digitais com o uso de recursos não digitais, oferecendo um ensino que possa motivar os alunos promovendo aprendizagem significativa.

\section{Método}

Este estudo delineia-se como uma pesquisa qualitativa, constituindo-se em um estudo de caso a partir da observação da interação de uma criança com o software Menino Curioso. O Estudo de Caso abarca uma investigação empírica que compreende um método abrangente, que trata da lógica de planejamento, das técnicas de coleta e de análise de dados, além de "descrever uma intervenção e o contexto na vida real em que ela ocorre", além de "ilustrar certos tópicos dentro de uma avaliação” (Yin, 2005, p. 34).

Nesta investigação, tem-se como objetivo refletir sobre o uso do software Menino Curioso no desenvolvimento das habilidades de decodificação pressupostas pela leitura. Logo, apresenta-se um caso individual com a intenção de que ele seja representativo, no sentido de "capturar as circunstâncias e condições de uma situação lugar-comum ou do dia-a-dia" (Yin, 2005, p. 63). Utilizaram-se como dados, entrevistas realizadas, individualmente, com a professora e com a mãe, além de observações de três sessões de atendimento.

\section{Participante}

O sujeito participante deste estudo é uma criança de 8 anos de idade que frequenta o $3^{a}$ ano do Ensino Fundamental de uma Escola Municipal, em uma cidade localizada no interior do Rio Grande do Sul. A criança reside com os pais e um irmão mais novo e faz uso do computador apenas em sua casa. Apesar de estar em atendimento neurológico há 6 anos, psicológico há 2 anos, fisioterápico há 4 anos e fonoaudiológico há 8 meses, não apresenta um diagnóstico fechado. Segundo a mãe da criança, o que os médicos encontraram nos exames foram "três cistos no cérebro" (sic).

$11 \mathrm{O}$ termo inconsciente é utilizado, nesse contexto, como ausência de consciência no momento da ação. A ação se realiza de forma automatizada, sem que o sujeito se dê conta.
Já, segundo relato de sua professora, a criança apresenta dificuldade no processo de escolarização, não é alfabetizada, não consegue reconhecer ou discriminar letras, tem dificuldades na linguagem, problemas com a coordenação motora, é muito agitada, além de não demonstrar interesse nas atividades solicitadas.

\section{Procedimentos}

O TCLE foi apresentado para a mãe do sujeito e assinado por ela. Na sequência, foram realizadas três sessões de atendimento individualizado, com cerca de 40 minutos cada, nas quais se observou a interação que a criança estabeleceu com o software Menino Curioso. A escolha desse software deveu-se à possibilidade de vir a apoiar o processo de alfabetização de forma dinâmica, lúdica e interativa. O software foi desenvolvido pelo professor José Antônio Borges (UFRJ) e contém onze jogos (Figurinhas, Combinum, Continha, Embaralhada, Inventor, Labirinto, Letrinhas, Liga pontinhos, Monta cena, Quebra-cabeça, Quadro de letras). O público-alvo são crianças da pré-escola até $5^{\circ}$ ano do Ensino Fundamental. Embora seja um software indicado para crianças com limitação visual - atende a maior parte dos critérios de acessibilidade -, também pode ser usado com crianças de visão normal (Santarosa \& cols., 2010).

Para a constituição do corpus da análise, foram realizados registros em forma de textos, evidenciados através da observação da interação da criança com o software Menino Curioso. A seguir, foi utilizada a análise textual discursiva (Moraes \& Galiazzi, 2007), de natureza qualitativa. A partir da análise e organização dos dados, duas categorias emergiram, com o intuito de tentar compreender o uso desse software no desenvolvimento das habilidades de decodificação pressupostas pela leitura: (1) Interação com a tecnologia digital; e (2) Leitura inicial - desenvolvimento das habilidades de decodificação pressupostas pela leitura.

A primeira categoria apontou os seguintes indicadores: (a) Capacidade e domínio para interagir com o computador (uso do mouse); (b) Capacidade e domínio para interagir com o software; (c) Identificação de características, como autonomia, espontaneidade, atenção e motivação no uso do software. Já a segunda categoria proveio dos indicadores: (d) Conhecimento prévio; (e) Identificação do signo gráfico (correspondência letra-som/discriminação de letras); (f) Desenvolvimento de um vocabulário visual (reconhecimento de palavras instantaneamente e/ou à primeira vista); (g) Desenvolvimento de uma consciência fonológica ou de habilidades metalinguísticas.

\section{Resultados e discussões}

Dentre os onze jogos disponibilizados no Software Menino Curioso, foram trabalhados apenas cinco deles: Figurinhas, Inventor, Labirinto, Letrinhas e Quadro de letras, atendendo aos objetivos deste estudo. Para fins de organi- 
zação e compreensão do processo serão apresentados os jogos e os resultados observados e discutidos - conforme as categorias e indicadores anteriormente mencionados - ao longo das três sessões realizadas com a criança.

Inicialmente, buscou-se deixar a criança livre para que pudesse escolher o jogo e familiarizar-se com a ferramenta digital. Nesse momento, tinha-se como meta verificar os indicadores referentes à primeira categoria: Interação com a tecnologia digital. Foi dito à criança o procedimento a ser realizado, o que a deixou alegre e, de certo modo, ansiosa para iniciar as atividades.

No que se refere a essa primeira categoria, foi possível observar - em todas as sessões - que a criança conseguiu atentar e se concentrar na maioria das solicitações provenientes do próprio software, agindo com autonomia, espontaneidade e motivação. Demonstrou um pouco de impaciência apenas quando o menino curioso repetia uma instrução que já havia sido dada. Esse fato pôde ser observado quando a criança clicava antes de o software terminar de fornecer a orientação. Com igual desenvoltura, ela não apresentou nenhuma dificuldade para manusear o mouse; pelo contrário, surpreendeu com sua habilidade motora e rapidez, apesar de manifestar dificuldades com a coordenação/motricidade na escola.

Em relação à segunda categoria, Leitura Inicial: desenvolvimento das habilidades de decodificação pressupostas pela leitura, vários aspectos podem ser discutidos. Os jogos foram escolhidos pelo próprio sujeito de maneira aleatória. No chamado Letrinhas - que tem como objetivo explorar o teclado, digitando as letras e conhecendo-as através de sua associação com palavras iniciadas por elas - já foi possível analisar um dos indicadores, isto é, a identificação do signo gráfico. Nesta atividade a criança é convidada a clicar em uma letra qualquer. Por exemplo, se ela clicar na letra $A$, uma voz diz "eu sou o $A$ de avião", seguida por uma imagem. Desse modo, esse jogo pode propiciar à criança o desenvolvimento de uma das principais habilidades exigidas pelo processo de decodificação em leitura: a correspondência letra-som.

Como já dito, para decodificar, a criança precisa dominar o código escrito, reconhecendo um signo gráfico por um nome ou por um som e, consequentemente, captar seu significado. Esses aspectos foram observados no momento em que se deu a interação do sujeito com esse jogo. A criança clicou em quase todas as letras do alfabeto, sem uma ordem definida. Dizia o nome da maioria das letras pelo menos duas vezes: uma antes de clicar na letra e a outra na sequência, quando verificava/percebia seus acertos ou erros.

Em alguns momentos, também, fez comentários, sorriu e brincou, como no caso da letra G: "G é de gato" (sic); e também com a letra $P$ : "o $P$ é de pato" (sic). Clicou várias vezes na letra $T$ (essa letra mostra a figura de um bebê levando um tapa) e na letra $M$ (a letra $M$ apresenta um bebê tomando mamadeira). Ao clicar na letra $R$, vogais foram mostradas e uma instrução foi dada com musicalidade: "A letra $u$ está correndo perigo, para salvá-la você precisa clicar no u". A criança clicou imediatamente e recebeu aplausos, bateu palmas junto e sorriu, demonstrando satisfação por ter acertado. O sujeito observado cometeu também alguns erros: disse que iria clicar na letra $K$, mas clicou na letra $Q$. Mencionou que digitaria a letra $Y$, mas clicou na letra $W$.

Nessa experiência, foram observados a motivação da criança e seu êxito quando verbalizava uma letra e a identificava pelo nome; algo que de modo convencional, segundo informações da professora, não acontece, pois a criança fica agitada, não demonstra interesse em realizar as atividades e tampouco discrimina as letras do alfabeto. Com o uso desse software educacional e lúdico, encontrou-se um sujeito ativo que fazia comentários sobre as letras e brincava com elas, apresentando mais acertos do que erros.

O outro jogo com o qual a criança interagiu, o Quadro de Letras, possibilita a escrita de diversas palavras em um quadro, usando as letras do alfabeto. Nesse jogo, outros indicadores foram analisados, como a importância de valorizar o conhecimento prévio da criança, o início do desenvolvimento da habilidade metalinguística e do vocabulário visual. A criança iniciou o jogo colocando e nomeando as letras em ordem alfabética $A, B, C, D$. Em seguida disse que queria escrever Chaves. Quando chegou próximo da letra $E$, solicitou uma confirmação: "Agora é o E?" (sic). Depois, indagou: "Agora é o S?" (sic). O observador não proporcionou à criança uma resposta assertiva, mas buscou mediar o processo, solicitando a ela que repetisse em voz alta a palavra e sugerindo que buscasse alguma alternativa para resolver sua dúvida.

Na sequência, referiu que "montaria" a palavra Shrek e, assim, o fez. Posteriormente, falou: "vou escrever agora Toy Story" (sic). Ao escrever TO falou "esqueci... é com (apontou para a letra Y)?" (sic). O observador novamente interfere, solicitando que pronunciasse a palavra, mesmo sendo um vocábulo estrangeiro. Ao oralizar, a criança escreve TOI e pergunta em seguida: "Está certo?" (sic). Expressou estranheza e escreveu novamente TOY, afirmando "É assim ó!" (sic). Por fim, quis "montar" a palavra Mr. Bean e escreveu $M E B N$, questionando novamente. Desta vez, o observador não interveio e o sujeito concluiu "Acho que não" (sic), abandonando a palavra.

Com essas observações, pode-se analisar que a própria criança, ainda que não conseguisse escrever de forma correta algumas das palavras sugeridas por ela mesma, podia detectar, quando tentava ler, que não estavam certas, do que se pode inferir o início do desenvolvimento de uma habilidade metalinguística. Apesar de demonstrar insegurança em alguns momentos, a criança brincava com as letras oralizando o nome delas. Relatou, ainda, que iria "montar" a palavra casa. Escreveu CAAS e questionou "tá certo?" (sic). Após sorrir, consertou CASA, sem a interferência do observador.

Outro aspecto que pode ser destacado nessa atividade, é o das palavras que são significativas para essa criança. Daí a importância de se investigar um dos indicadores referente aos conhecimentos prévios do sujeito. Conhecer as habilidades linguísticas, o conhecimento de mundo e os interesses da criança pode auxiliar no processo de alfabe- 
tização. No caso em questão, foi possível saber que esse sujeito gostava de desenhos, filmes e programas televisivos.

Esse jogo também possibilitou discutir acerca de outro indicador: o desenvolvimento do vocabulário visual. Nesse sentido, a criança demonstrou estar construindo seu vocabulário visual, visto que de outro modo - se fosse apenas em função da oralização-, ela deixaria a palavra TOY como TOI, não percebendo que havia errado, principalmente por se tratar de um vocábulo não existente na língua portuguesa. Esse dado mostra que o sujeito desenvolveu o reconhecimento instantâneo dessa palavra: "é assim ó - TOY" (sic).

Ainda em relação a esse jogo, foi solicitado à criança que escrevesse algumas palavras simples, como bolo, mama e mesa. Ela teve certa dificuldade em formá-las, escrevendo, sem ajuda mama e com auxílio, boo e mea. Quando foi mencionado que algumas letras estavam faltando, a criança não conseguiu identificar o "lugar" em que elas deveriam ser inseridas a fim de formar a palavra corretamente. Entretanto, sabia que se tratavam das letras $L$ (bo/o) e $S$ (mesa).

Outro jogo utilizado pela criança foi o Inventor, que permite misturar as letras para formar várias palavras, promovendo o desenvolvimento da consciência fonológica. Esse jogo tem três níveis de dificuldade. O nível mais fácil foi o selecionado pelo observador, que objetivava a união das vogais. No caso, embora a criança tenha unido duas vogais que não formaram nenhuma palavra, por exemplo, io, ela se divertiu com o jogo, especialmente quando clicou nas vogais $e+u$ (que era seguida pela oralização: eu sou um menino curioso!) ou em $u+i$ (que verbalizava, na sequência: ui, que dor de barriga!). A criança, portanto, não denotou dificuldades para lidar com as vogais, identificando-as corretamente. Considerando que esse jogo propicia o entendimento acerca das relações entre letras e sons, nota-se que a criança, no nível de dificuldade mais avançado (que une sílabas e forma palavras) ainda precisa de auxílio.

O Labirinto, com dois níveis de dificuldade, foi o jogo em que a criança teve seu pior desempenho e, por isso, não quis realizar muitas tentativas, parecendo frustrada. O nível mais fácil desse jogo consiste em um labirinto pequeno que forma palavras consideradas simples. Porém, o sujeito não conseguiu ler nenhuma das três palavras visualizadas: jogo, sorvete, carrinho.

Como visto até o momento, o material a ser oferecido ao aluno pode contribuir para o seu interesse, para a sua motivação, e pode também propiciar avanços em seu desenvolvimento, especialmente quando oferece desafios (Solé, 1998). Entretanto, como reiterado por Santarosa e cols. (2010), a escolha do software educacional precisa ser coerente com os objetivos do professor, o qual deve investigar as possibilidades dos jogos e explorá-los no uso com seus alunos. Acrescente-se a isso a necessidade de conhecer os níveis de desenvolvimento do aprendiz, para não correr o risco de inibir seu desenvolvimento ao invés de avançá-lo.

Diferentemente dos jogos anteriores - em que o observador, quando interferiu, teve a intenção de atuar na ZDP da criança, isto é, de auxiliá-la na realização de uma tarefa, para que, no futuro, ela possa executá-la de forma autôno- ma -, acredita-se que o Labirinto exigiu da criança ações além de suas possibilidades, o que resultou em impaciência e esquiva.

O jogo de que a criança mais gostou foi o Figurinhas, que possibilita a montagem de um álbum, associando letras a palavras iniciadas com essas letras. O sujeito recebe uma figurinha para colar no álbum a cada associação feita. Foi possível analisar os indicadores de identificação do signo gráfico, que permite nomear letras e associá-las ao som. Aqui, a criança verbalizou a maior parte das letras de forma adequada, pronunciando-as novamente quando verificava que havia cometido um erro. Os equívocos mais frequentes foram com as letras $K, Q, H, Y, W$ e $X$ as quais podem ser, de fato, mais difíceis para qualquer criança que se encontre em processo de alfabetização. Durante essa atividade, a criança mencionou várias vezes que havia achado esse jogo muito legal. Após três sessões, deu-se por encerrada a proposta realizada, e a criança saiu da sala perguntando "Amanhã eu venho de novo?" (sic).

\section{Considerações finais}

O estudo teve como objetivo contribuir para uma reflexão sobre o uso do software Menino Curioso no desenvolvimento das habilidades de decodificação pressupostas pela leitura. O uso do software Menino Curioso permitiu inferir que é possível mediar a aprendizagem da leitura inicial, ainda que com uma criança que apresente dificuldades no processo de escolarização.

O participante revelou, na interação com o software, o desenvolvimento de habilidades implicadas pela leitura, tais como: a identificação de parte dos signos gráficos, o início do desenvolvimento de habilidades metalinguísticas, e denotou estar em processo de construção de um vocabulário visual. Essas habilidades, normalmente, passam despercebidas pela professora, o que confirma que as tecnologias digitais têm se apresentado como aliadas no processo de ensino e aprendizagem, especialmente para a aprendizagem dos alunos que exigem algum tipo de educação especializada (Santarosa \& cols., 2010).

Destaca-se o papel essencial do docente, o qual pode oferecer um material desafiador para o aluno, considerando sua ZDP, de modo que a aprendizagem da leitura não ocorra de forma mecanizada, mas significativa. Os jogos oportunizados para o sujeito observado provocaram-lhe espontaneidade, autonomia e motivação, características que só puderam ser evidenciadas devido à mediação do observador, tendo em vista que a tecnologia é um suporte que auxilia a aprendizagem, mas que por si só é insuficiente.

Considerando o exposto acima, faz-se necessário destacar a dificuldade que algumas escolas possuem para ter acesso ao uso de computadores e demais ferramentas tecnológicas que se mostram relevantes para o ensino, além da formação adequada dos professores, visando potencializar o uso da tecnologia para fins educacionais. 
Feitas essas ponderações, reconhece-se as limitações deste artigo, haja vista o pouco número de sessões realizadas com o sujeito em questão. Entretanto, destaca-se o potencial demonstrado pela criança em um período tão restrito. Sugere-se que novos estudos sejam realizados, especialmente com o uso de softwares educacionais que possam auxiliar no desenvolvimento das habilidades de decodificação pressupostas pela leitura, o que permitirá constatar que muitas crianças com aparentes limitações cognitivas podem aprender a ler, desde que tenham acesso a uma mediação diferenciada e alternativa.

\section{Referências}

Alliende, F. \& Condemarín, M. (1987). A Leitura: Teoria, avaliação e desenvolvimento. Porto Alegre: Artmed.

Alliende, F. \& Condemarín, M. (2005). A Leitura: Teoria, avaliação e desenvolvimento (8a. ed.). Porto Alegre: Artmed.

Facci, M.G.D. \& Souza, M.P.R. (2014). O processo de avaliaçãointervenção psicológica e a apropriação do conhecimento: uma discussão com pressupostos da escola de Vigotski. Revista Psicologia Política, 14 (30), 385-403.

Ferreiro, E. \& Teberosky, A. (1999). Psicogênese da língua escrita. Porto Alegre: Artmed.

Kleiman, A. (2011). Texto e Leitor: Aspectos cognitivos da leitura (14a ed.). São Paulo: Pontes Editores.

Kleiman, A. (2012). Oficina de leitura - teoria e prática (14a ed.). São Paulo: Pontes.

Luria, A. R. (1988). O desenvolvimento da escrita na criança. In: Vygotsky, L.S.; Luria, A.R.; Leontiev, A. Linguagem, desenvolvimento e aprendizagem ( $4^{\mathrm{a}}$ ed., pp. 143-190). São Paulo: Ícone.

Moraes, R. \& Galiazzi, M. (2007). Análise textual discursiva. Ijuí: Editora Unijuí.
Santarosa, L.M.C., Conforto, D., Passerino, L. M., Estabel, L.B., Carneiro, M. L.F., \& Geller, M. (2010). Tecnologias digitais acessíveis. In: Santarosa, L. M. C. (Org.), Software Educacional e Objetos de Aprendizagem: construindo instrumentos de mediação (pp. 259-287). Porto Alegre: JSM Comunicações.

Soares, M. (2002). Novas práticas de leitura e escrita: letramento na ciber-cultura. Educação \& Sociedade, 23 (81), 143-160.

Soares, M. (2003). Letramento e Escolarização. In: Ribeiro, V.M. (Org.), Letra-mento no Brasil: reflexões a partir do INAF, 2001 (pp. 89-113). São Paulo: Global.

Solé, I. (1998). Estratégia de leitura (6a ed.). Porto Alegre: Artmed.

Souza, M.P.R. (2008, outubro). Medicalização na educação infantil e no ensino fundamental e as política de formação docente retornando à patologia para justificar a não aprendizagem escolar: a medicalização e o diagnóstico de transtornos de aprendizagem em tempos de neoliberalismo. Trabalho apresentado na $31^{\text {a }}$ Reunião Anual da ANPEd, Caxambu - Minas Gerais. Recuperado: 17 abr. 2017. Disponível: http://31reuniao.anped.org.br/4sessao_ especial/se $\% 20-\% 2012 \% 20-\% 20$ marilene $\% 20$ proena $\% 20$ rebello\%20de\%20souza\%20-\%20participante.pdf.

Vasconcellos, V.M.R. \& Valsiner, J. (1995). Perspectivas coconstrutivistas na educação. Porto Alegre: Artmed.

Vygotski, L.S. (1996). Obras escogidas (Vol. 5). Madrid: Visor.

Vygotski, L.S. (1997). Obras escogidas (Vol. 5). Madrid: Visor.

Vygotsky, L.S. (1991). A formação social da mente (4 ed.). São Paulo: Martins Fontes.

Vygotsky, L. S. (1998). Pensamento e Linguagem (2a ed.). São Paulo: Martins Fontes.

Vygotsky, L.S., Luria, A.R., \& Leontiev, A. N. (1998). Linguagem, Desenvolvimento e Aprendizagem (6a ed.). São Paulo: Ícone.

Yin, R.K. (2005). Estudo de Caso: planejamento e métodos (3a ed.). Porto Alegre: Bookman.

Recebido em: 10 de novembro de 2016 Aprovado em: 13 de junho de 2017 


\section{Sobre as autoras}

Aline Sberse Sengik (alinesengik@hotmail.com)

Mestre em Educação (UCS), Especialista em Neuropsicologia (UNIARA) e Psicologia da Saúde (UPF), Graduada em Psicologia (PUCRS) com Formação Pedagógica (UCS). Psicóloga da Prefeitura Municipal de Lagoa Vermelha/RS.

Carla Beatris Valentini (cbvalent@ucs.br)

Doutora em Informática na Educação (UFRGS), Mestre em Psicologia (UFRGS). Professora do corpo permanente do Programa de PósGraduação em Educação (UCS). Universidade de Caxias do Sul. Caxias do Sul - RS

Jordana Wruck Timm (jordana.timm@acad.pucrs.br)

Doutoranda em Educação (PUCRS), Mestre em Educação (UCS), Especialista em Psicopedagogia. Bolsista CAPES.

O presente texto é derivado de discussões realizadas na disciplina "Seminário Avançado em Tecnologia e Educação", ministrada pela professora Carla Beatris Valentini. As coautoras são bolsistas CNPq e CAPES, respectivamente. 